RESEARCH ARTICLE

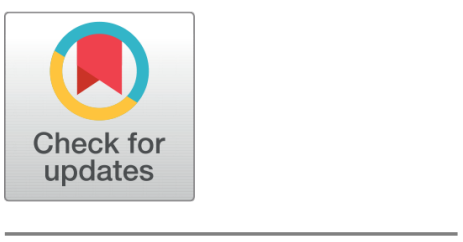

open ACCESS

Received: 13.03 .2021

Accepted: 04.05.2021

Published: 18.05 .2021

Citation: Kandula R, Jain RS, Kandula S, Reddy BS (2021)

Compartmental model to estimate bile acid concentration in different clinical manifestation. Indian Journal of Science and Technology 14(18): 1422-1433. https://doi.org/ 10.17485/IJST/v14i18.434

* Corresponding author.

Tel: +91-984-992-8294

ramana.kandula@gmail.com

Funding: None

Competing Interests: None

Copyright: (c) 2021 Kandula et al. This is an open access article distributed under the terms of the Creative Commons Attribution License, which permits unrestricted use, distribution, and reproduction in any medium, provided the original author and source are credited.

Published By Indian Society for Education and Environment (iSee)

ISSN

Print: 0974-6846

Electronic: 0974-5645

\section{Compartmental model to estimate bile acid concentration in different clinical manifestation}

\author{
Ramanamoorthy Kandula1*, Rupali S. Jain ${ }^{2}$, Sandhya Kandula ${ }^{3}$, \\ B Surendranath Reddy ${ }^{2}$
}

1 Assistant Professor, Department of Mathematics, B V Raju Institute of Technology, Narsapur-502313, Medak-Dist. T.S, India. Tel.: +91-984-992-8294

2 Assistant Professor, Department of Mathematics, Swami Ramanand Teerth Marathwada University, Nanded-431606, M.S, India.

3 Assistant Professor, Department of Pharmacology, Vishnu Institute of Pharmaceutical Education and Research, Narsapur-502313, Medak-Dist., T.S, India.

\section{Abstract}

Objectives: To design a bio-compartmental model of enterohepatic circulation; and to estimate the concentration of bile acid in a different compartment and to understand the various pathological states connected to bile concentration. Methods: The model is based on parameters of volume of bile juice, the mass of bile acid, and the rate of bile secretion in all compartments. The model estimates various clinical manifestations of gallbladder and intestine describing the variable concentration of bile acid based on pathological state and application of mathematical simulation of fractional derivative (MATLAB). Findings: Compatibility of the model results considering pathological data allows us to estimate bile acid concentration in different pathological conditions, thus alters the physiology of enterohepatic circulation. Based on a pathological case the bile acid concentration was estimated and then the fractional derivative was applied to understand the severity of bile-related disorder with the help of mathematical simulation. The graphical results are obtained by applying fractional-order derivative (A Caputo sense) in different pathological cases depicts the varying bile acid concentration in the intestine, liver, and gallbladder comparative to a normal concentration. All findings clearly mentioned in section 4 (Results and Discussion). Novelty/Applications: Mathematical simulation of deposition of bile acid in conjugation with enterohepatic circulation, compartment model helps to understand the pathological disorder and etiology with the clinical symptoms of bile secretion.

Abbreviations: GB: Gallbladder; ODE: Ordinary differential equations; FODE: Fractional order differential equations

Keywords: Intestine; Gallbladder; Liver; Enterohepatic circulation; Bile acid concentration; Mathematical modeling. 


\section{Introduction}

\subsection{Regulation of bile homeostasis}

The synthesis of bile essentially helps in lipid metabolism. The hepatic system secretes $500 \mathrm{ml}$ to $1200 \mathrm{ml}$ bile in the liver every day and around $75 \%$ is allowed to flow towards the gallbladder in the form of a 6 to 8 pulsatile pattern, and the rest volume of bile directly flows to the lower intestine ${ }^{(1)}$. The intake of the fat-rh meal allows approximately $4 \mathrm{gm}$ to $6 \mathrm{gm}$ (i.e., $4000 \mathrm{mg}$ to $6000 \mathrm{mg}$ ) to bile acid pool per cycle and undergoes 4 to 6 cycles every day secreted by the duodenum and enhances metabolism of lipid, following the $95 \%$ of bile is reabsorbed by the liver during enterohepatic circulation and rest $5 \%$ excreted in feces ${ }^{(2,3)}$.

The atony of gallbladder functioning or intestinal resection leads to abnormal bile secretion and its circulation, which associate to cause lipid imbalance due to lack of its metabolism and aligning disorder of high risk of cholesterol and bile acid in the systemic circulation ${ }^{(4)}$. Even though the gallbladder is considered to be not so important organ for survival, but its role in bile acid storage and concentrating its composition following the enterohepatic circulation effectively helps in lipid metabolism and absorption ${ }^{(5)}$. Abnormal functioning of bile or intestinal bile secretion arises due to various pathological disorders such as biliary obstruction, biliary fistula, cholecystectomy, ileal resection, portal-systemic venous shunting, and gallstone. The disturbances in the membrane protein transport of bile acid also affect the rate of bile transport during enterohepatic circulation and further alter the bile acid concentration ${ }^{(6)}$. The bile acid biosynthesis is enhanced by the presence of cholesterol; in turn, bile acid biosynthesis can be deteriorated by a defect in the steroid nucleus, side-chain, or its conjugation ${ }^{(7)}$.

\subsection{Gallbladder and intestinal disorders}

Gallbladder disorders are relatively common around most of the globe. The overall prevalence of gallbladder disease in the United States, Western Europe, and India is $10 \%$ to $20 \%{ }^{(8)}$. The various underlying gallbladder and intestinal disorders alter the rate constant of bile circulation which in turn abnormally increases or decreases bile acid concentration in the intestine, gallbladder, or plasma based on the site of atony. The gallstone formation is the most common type of gallbladder disorder ${ }^{(8)}$, while the resorption of bile component in the gallbladder is increased leaving the concentrated and hard component of bile which forms solid stone and remain lodge in the neck of the gallbladder and bile duct, bile acid composition varies and trigger to cause cholecystitis ${ }^{(9)}$. Such a physiological state enhances the severity and causes biliary obstruction and biliary fistula ${ }^{(10)}$. Biliary obstruction is a condition lead by increase resorption of bile acid into plasma and induces toxicity in plasma and deposit in the urinary system while its excretion through urine also increased ${ }^{(11)}$. Furthermore, the enterohepatic circulation is reduced and a lack of synthesis of secondary bile acid in the small intestine is seen. If there is an increase in bile acid absorption only through the portal venous system causes portal-systemic venous shunting ${ }^{(12)}$. The biliary fistula is a state indulged to divert the bile acid from entering into the small intestine and due to lack of bile circulation from the gallbladder to the intestine, the workload of synthesis of bile acid in the small intestine is increased up to 20 folds ${ }^{(10)}$. The surgically induced pathology is cholecystectomy, where the gallbladder is completely removed and the bile duct is directly connected to the small intestine, so the bile acid pool is stored in the intestine while fasting and on ingestion of a meal, the stored bile acid is conveyed to lower intestine to synthesize secondary bile acid and metabolism of lipids ${ }^{(9)}$.

The surgically induce intestinal abnormality that alters bile acid synthesis rate is ileal resection. The resection of terminal ileal up to $100 \mathrm{~cm}$ causes malabsorption of bile acid and decreases bile acid secretion, while increases the synthesis of bile acid in the intestine up to 20 folds which compensates the loss amount of bile acid due to resection ${ }^{(13)}$.

\subsection{Model design}

The previously developed compartment model explained the essence of gallbladder filling and evacuation in various instances such as food composition, age, and weight of the patient ${ }^{(14)}$. Supporting the study, we designed the three-compartment model of enterohepatic circulation of bile to better understand the varying concentration of bile acid leading to specific clinical manifestation with the clinical data available ${ }^{(15)}$. Here in this study, the altered rate constant and pathological state of the intestine and gallbladder is considered to better understand the bile acid concentration in different compartments ${ }^{(16)}$. The chemical structural defects of bile acid affecting its concentration are not considered in the present study.

Consequently, the secretion and circulation of bile is a prime event and in the condition of its physiological divergence helps to draw the exact pathological state and able to locate any inefficiency function of intestine, liver, or gallbladder with the help of estimating the concentration of bile acid ${ }^{(17)}$ by mathematical simulation. The fact regarding the FODE A Caputo model applied in the present research is most well-known used by scientists to trace dynamic of diseases condition in society. The scientists Khan and Atangana derived a model and formulated the numerical solution using the fractional derivative to trace the transmission of novel coronavirus from the bats and seafood via unknown host to the people in society ${ }^{(18)}$. Similarly, 
we aimed to find the bile acid concentration in various diseases ailment and understand the severity of diseases condition by estimating its concentration even at non-integer case; and the uniqueness of our research is to apply the FODE A Caputo model to solve the pharmacokinetic model of enterohepatic circulation.

\section{Materials and methods}

\subsection{Modeling bile circulatory system}

The compartment model is designed to estimate the bile acid concentration in the intestine, liver, and gallbladder considering the clinical manifestation of various pathological states of gallbladder and intestine. The pharmacokinetics of bile acid during enterohepatic circulation is associated with the volume of distribution of bile, the rate constant, and the mass of bile acid in the enterohepatic biliary system ${ }^{(19)}$. The bile circulation is outlined with three compartments as shown in Figure 1, where bile from the liver is stored and concentrated in the gallbladder in a pulsatile manner, following the meal consumption enterohepatic circulation of about $75 \%$ of bile from the gallbladder to the intestine takes place for lipids metabolism ${ }^{(14,20)}$. Finally, $95 \%$ bile acid pool is restored from intestine to liver with $5 \%$ excretion $^{(21)}$.

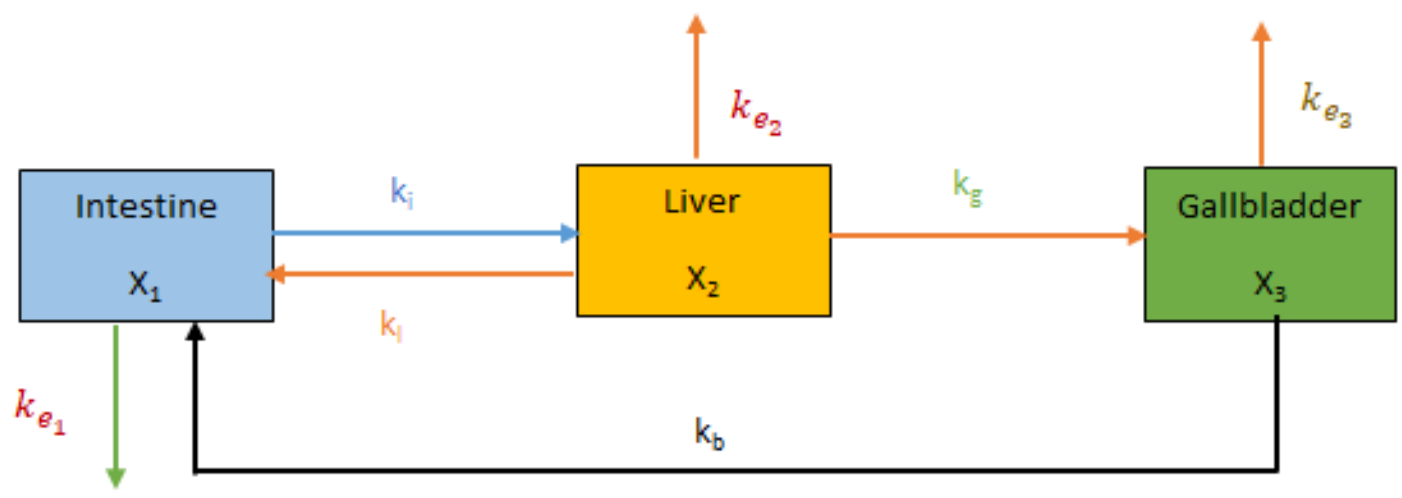

Fig 1. A schematic representation of three compartment model of biliary circulatory system, compartment $\mathrm{X}_{1}$ indicates Intestine, compartment $\mathrm{X}_{2}$ as Liver and compartment $\mathrm{X}_{3}$ as Gallbladder

The bio-mathematical simulation to analyze the variable bile acid concentration in the gallbladder and intestinal etiology is investigated by applying the FODE (Fractional order differential equation) A Caputo model and by using high-defined technical computing software tool MATLAB (version R2020a).

The following three simultaneous ODE's explains the rate of changes of bile acid mass in three compartments respectively (Eq. 1, Eq. 2, and Eq. 3)

$$
\begin{array}{lll}
\frac{d x_{1}}{d t}=-\left(k_{i}+k_{e_{1}}\right) x_{1}+k_{b} x_{3}+k_{l} x_{2} & ; & x_{1}(0)=x_{01} \\
\frac{d x_{2}}{d t}=-\left(k_{g}+k_{e_{2}}+k_{l} x_{12}\right) x_{2}+k_{i} x_{1} ; & x_{2}(0)=x_{02} \\
\frac{d x_{3}}{d t}=k_{g} x_{2}-\left(k_{b}+k_{e_{3}}\right) x_{3} & ; & x_{3}(0)=x_{03}
\end{array}
$$

Parameter values are:

Amount of bile acid in the intestine $\left(\mathrm{x}_{01}\right)=3 \times 10^{4} \mathrm{mg}^{(2)}$,

Amount of bile acid in the liver $\left(\mathrm{x}_{02}\right)=12 \times 10^{4} \mathrm{mg}^{(2)}$,

Amount of bile in the gallbladder $\left(\mathrm{x}_{03}\right)=8160 \mathrm{mg}^{(2)}$,

Rate of constant from Intestine to Liver $\left(\mathrm{k}_{i}\right)=0.695 / \mathrm{min} .{ }^{(13)}$, 
Rate of the constant from Liver to Intestine $\left(\mathrm{k}_{l}\right)=0.695 / \mathrm{min} .{ }^{(21)}$,

Rate of the constant from Liver to Gallbladder $\left(\mathrm{k}_{g}\right)=0.625 / \mathrm{min} .{ }^{(13,15)}$,

Rate of the constant from Gallbladder to Intestine $\left(\mathrm{k}_{b}\right)=0.3 / \mathrm{min} .{ }^{(3)}$,

Rate of elimination from Intestine $\left(k_{e_{1}}\right)=0.034 / \mathrm{min} .{ }^{(13)}$,

Rate of elimination from Liver $\left(k_{e_{2}}\right)=0.02 / \min ^{(22)}$,

Rate of elimination from Gallbladder (Rate of resorption) $\left(k_{e_{3}}\right)=0.25 / \mathrm{min}^{(3)}$.

Here, the compartment model explains the bile circulation from the liver to gallbladder and intestine, further from gallbladder to the intestine, and bile pool back from the intestine to the liver. While the liver conveys a large volume of bile to store in the gallbladder for about 6 to 8 times in a pulsatile pattern and small amount directly enters into the small intestine. For about 4 to 6 cycles per day, the enterohepatic circulation from the gallbladder to intestine occurs and the total bile pool size from the intestine back to the liver is about $12-18 \mathrm{gm}$ of bile acid/day.

The model equations include $\mathrm{x}_{01}, \mathrm{x}_{02}$, and $\mathrm{x}_{03}$ indicate the initial amount of bile acid in the intestine, liver, and gallbladder respectively; whereas $\mathrm{k}_{i}, \mathrm{k}_{l}, \mathrm{k}_{g}$, and $\mathrm{k}_{b}$ rate constant from the intestine, liver, and gallbladder. The rate of elimination from intestine, liver, and gallbladder is considered as $k_{e_{1}}, k_{e_{2}}, k_{e_{3}}$ respectively.

\section{Calculation}

A set of three fractional order differential equations has been simplified by using A Caputo model and pharmacokinetic simulation is investigated using high-throughput computing software tool MATLAB (version R2020a).

\subsection{Fractional order differential equations- A Caputo model}

Definition (22): Suppose that $f(t) \in C(a, b]$ and $c_{D_{t}^{\alpha} f(t)} \in C(a, b]$, for $m-1<\alpha \leq m$,

$$
m \in \mathbb{N}, \text { then } \quad c_{D_{t}^{\alpha} f(t)}=\left\{\begin{array}{rc}
\frac{1}{\Gamma(m-\alpha)} \int_{0}^{t} \frac{f^{(m)}(\tau)}{(t-\tau)^{\alpha+1-m}} d \tau, & m-1<\alpha<m \\
\frac{d^{m}}{d t^{m}} f(t), & \alpha=m
\end{array}\right.
$$

is called the Caputo fractional derivative of order $\alpha>0 . \alpha \in[0,1]$

where the symbol $\Gamma(\cdot)$ denotes the gamma function.

By applying the A Caputo derivative [ref. (22), from eqn.4.1] to above equations (1) - (3), we get

$$
\begin{array}{lll}
c_{D_{t}^{\alpha}} x_{1}=-\left(k_{i}+k_{e_{1}}\right) x_{1}+k_{b} x_{3}+k_{l} x_{12} ; & x_{1}(0)=x_{01} \\
c_{D_{t}^{\alpha} x_{2}}=-\left(k_{g}+k_{e_{2}}+k_{l}\right) x_{2}+k_{i} x_{1} ; & x_{2}(0)=x_{02} \\
c_{D_{t}^{\alpha} x_{3}}=k_{g} x_{2}-\left(k_{b}+k_{e_{3}}\right) x_{3} & ; & x_{3}(0)=x_{03}
\end{array}
$$

Here, ' $c_{D_{t}^{\alpha}}$ ' denotes the Caputo derivative with respect to ' $\mathrm{t}$ ' of fractional order ' $\alpha$ ', and the m-value is taken as 1 .

By lemma,

Lemma (22): Suppose that $f(t) \in C[a, b]$ and $c_{D_{t}^{\alpha} f(t)} \in C[a, b]$, for $0<\alpha \leq 1$, then we have,

$f(t)=f(a)+\frac{1}{\Gamma(\alpha)} \quad c_{D_{t}^{\alpha} f(\xi)}(t-a)^{\alpha}$. With $a \leq \xi \leq t, \forall t \in(a, b)$.

Then, equations (4) to (6) becomes

From Eqn. (4)

$$
x_{1}(t)=x_{1}(a)+\frac{1}{\Gamma(\alpha)}\left[-\left(k_{i}+k_{e_{1}}\right) x_{1}+k_{b} x_{3}+k_{l} x_{2}\right](t-a)^{\alpha}
$$

when $\mathrm{a}=0$, eqn. (7) becomes,

$$
x_{1}(t)=x_{1}(0)+\frac{1}{\Gamma(\alpha)}\left[-\left(k_{i}+k_{e_{1}}\right) x_{1}+k_{b} x_{3}+k_{l} x_{2}\right] t^{\alpha}
$$




$$
\therefore x_{1}(t)=\frac{x_{01} \Gamma(\alpha)+k_{b} x_{3} t^{\alpha}+k_{l} x_{2} t^{\alpha}}{\Gamma(\alpha)+\left(k_{i}+k_{e_{1}}\right) t^{\alpha}}
$$

From Eqn. (5)

$$
x_{2}(t)=x_{2}(a)+\frac{1}{\Gamma(\alpha)}\left[-\left(k_{g}+k_{e_{2}}+k_{l} x_{12}\right) x_{2}+k_{i} x_{1}\right](t-a)^{\alpha}
$$

when $\mathrm{a}=0$, eqn. (9) becomes,

$$
\begin{gathered}
x_{2}(t)=x_{2}(0)+\frac{1}{\Gamma(\alpha)}\left[-\left(k_{g}+k_{e_{2}}+k_{l}\right) x_{2}+k_{i} x_{1}\right] t^{\alpha} \\
\therefore x_{2}(t)=\frac{x_{02} \Gamma(\alpha)+k_{i} x_{1} t^{\alpha}}{\Gamma(\alpha)+\left(k_{g}+k_{e_{2}}+k_{l}\right) t^{\alpha}}
\end{gathered}
$$

From Eqn. (6)

$$
x_{3}(t)=x_{3}(a)+\frac{1}{\Gamma(\alpha)}\left[k_{g} x_{2}-\left(k_{b}+k_{e_{3}}\right) x_{3}\right](t-a)^{\alpha}
$$

when $\mathrm{a}=0$, eqn. $(11)$ becomes,

$$
\begin{gathered}
x_{3}(t)=x_{3}(0)+\frac{1}{\Gamma(\alpha)}\left[k_{g} x_{2}-\left(k_{b}+k_{e_{3}}\right) x_{3}\right] t^{\alpha} \\
\therefore x_{3}(t)=\frac{x_{03} \Gamma(\alpha)+k_{g} x_{2} t^{\alpha}}{\Gamma(\alpha)+\left(k_{b}+k_{e_{3}}\right) t^{\alpha}}
\end{gathered}
$$

From equations (10), and (12) we get,

$$
\therefore x_{3}(t)=\frac{x_{03} \Gamma(\alpha) Q+k_{g} x_{02} \Gamma(\alpha) t^{\alpha}+k_{g} k_{i} x_{1} t^{2 \alpha}}{Q . R}
$$

Where $\mathrm{Q}=\Gamma(\alpha)+\left(k_{g}+k_{e_{2}}+k_{l}\right) t^{\alpha} ; \mathrm{R}=\Gamma(\alpha)+\left(k_{b}+k_{e_{3}}\right) t^{\alpha}$

Substitute eqns. (9), and (13) in Eqn. (8) we get

$$
\therefore x_{1}(t)=\frac{x_{01} \Gamma(\alpha) Q R+x_{03} k_{b} \Gamma(\alpha) Q t^{\alpha}+x_{02} k_{b} k_{g} \Gamma(\alpha) t^{2 \alpha}+x_{02} k_{l} \Gamma(\alpha) R t^{\alpha}}{P Q R-k_{b} k_{g} k_{i} t^{3 \alpha}-k_{l} k_{i} t^{2 \alpha} R}
$$

Where $\mathrm{P}=\Gamma(\alpha)+\left(k_{i}+k_{e_{1}}\right) t^{\alpha}$

\subsection{Mathematical simulation: The parameter conditions}

The simulation estimates the variable bile acid concentration in various conditions of clinical manifestation of gallbladder and intestine. The model parameter values have been calculated using available clinical data and some values have been directly considered from previously proven experimental data of gallbladder motility.

From the previous clinical data, the mass of bile acid in the intestine, liver, and gallbladder is considered as $30 \mathrm{gm}$, $12 \mathrm{gm}$, and $8.16 \mathrm{gm}$ respectively. Accordingly, the volume of bile circulation varies in all compartments based on its capacity and synthesis rate of bile, as mentioned the volume of bile was found to be $\mathrm{v}_{1}=562 \mathrm{ml} / \mathrm{day}, \mathrm{v}_{2}=1000 \mathrm{ml} /$ day, $\mathrm{v}_{3}=750 \mathrm{ml} /$ day in the intestine, liver, and gallbladder ${ }^{(21)}$; the exclusion of volume of excretion is considered. From the available experimental data, the rate constant from the liver to the intestine is $0.695 / \mathrm{min}$ and in turn, the rate constant from the intestine to the liver is assumed as $0.695 / \mathrm{min}$ based on bile pool size. Also, the rate constant in a normal individual from the gallbladder to the intestine is $0.3 / \mathrm{min}$ in the first 20 minutes after a meal. The rate of elimination from the intestine, liver, and gallbladder is $0.034 / \mathrm{min}, 0.02 / \mathrm{min}$, and $0.25 / \mathrm{min}$ respectively.

Initially, at a normal rate of secretion the bile acid concentration in all compartments is analyzed. Later, the bile acid concentration in various clinical manifestations is estimated as per the etiological condition of abnormality in the gallbladder and intestine. 


\section{Results and Discussion}

The mathematical application of fractional order differential equation is considered for analysis of bile acid concentration in compartments of intestine, liver, and gallbladder. The Figure 2a indicates at $\alpha=0.5$ and normal rate constants of bile secretion $\left(\mathrm{k}_{a}, \mathrm{k}_{b}, k_{e_{1}}, k_{e_{2}}, k_{e_{3}}\right)$, the bile concentrations decrease in intestine and gallbladder gradually after 20 mins of meal intake, and simultaneously bile concentration increases in liver $c_{2}$.

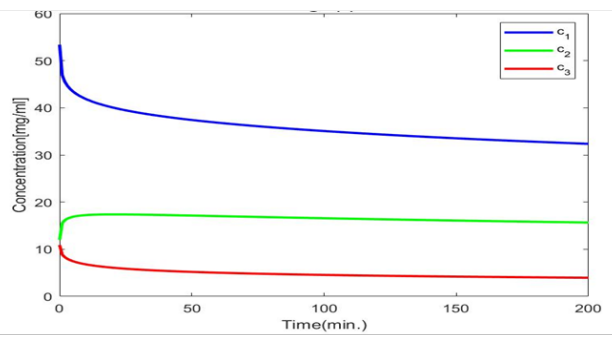

A

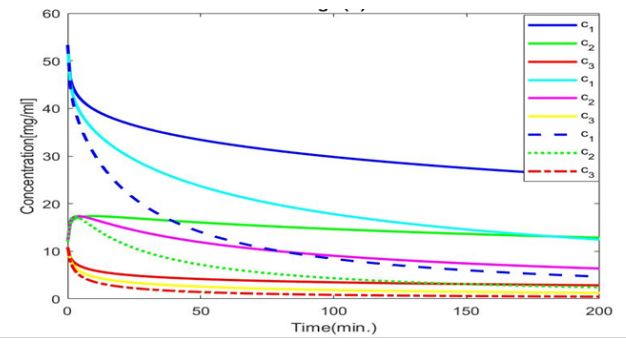

B

Fig 2. (a) Bile concentration in Intestine, Liver, and Gallbladder when all above values given in Table 1, and $\alpha=0.5$. (b) Bile concentration in Intestine, Liver, and Gallbladder when all values given in Table 1 , and $\alpha=0.6,0.8$, and 1.0.

In all graphs, $c_{1}=$ Bile concentration in Intestine; $c_{2}=$ Bile concentration in Liver, and $c_{3}=$ Bile concentration in Gallbladder.

Figure $2 \mathrm{~b}$ investigates bile acid concentration at different $\alpha$ values i.e., $0.6,0.8$, and 1.0 with normal conditions of the rate of bile secretion and its volume as per model parameter value. The graphical analysis represents that as $\alpha$ value increases; the bile concentration in all the compartments i.e., intestine, liver, and gallbladder drastically decreases. Initially in compartment $\mathrm{X}_{1}$, $\mathrm{X}_{2}$ and $\mathrm{X}_{3}$ the bile concentration is $53.38 \mathrm{mg} / \mathrm{ml}, 12.00 \mathrm{mg} / \mathrm{ml}$ and $10.88 \mathrm{mg} / \mathrm{ml}$ respectively. As time passes the concentration drastically and quickly decreases till 20 mins and at 20 mins the bile concentration in each compartment was found to be $37.31 \mathrm{mg} / \mathrm{ml}, 17.12 \mathrm{mg} / \mathrm{ml}$, and $5.16 \mathrm{mg} / \mathrm{ml}$ respectively. Following the $20 \mathrm{mins}$, the bile concentration gradually and slowly decreases till the ingestion of the next meal; at 60 mins the bile concentration was found to be $32.51 \mathrm{mg} / \mathrm{ml}, 15.72 \mathrm{mg} / \mathrm{ml}$, $3.98 \mathrm{mg} / \mathrm{ml}$ in compartment $\mathrm{X}_{1}, \mathrm{X}_{2}$, and $\mathrm{X}_{3}$ respectively. In the case of an unknown etiology of the biliary circulatory system, such mathematical simulation helps to underline the expected clinical manifestation of specific etiology of intestine, liver, or gallbladder.

In case-1 (Figure 3 a), the biologically known fact that the rate of bile resorption from the gallbladder is high due to biliary obstruction, and secretion of bile acid in the intestine decreases (21).

Co-relating by mathematical simulation, Figure 3a explains the etiology of biliary fistula, as the rate of bile resorption from the gallbladder $k_{e_{3}}$ increases with $\alpha=0.5$ thus bile acid concentration in compartment- $\mathrm{X}_{3}$ i.e., gallbladder decreases from 10.88 $\mathrm{mg} / \mathrm{ml}$ at $0 \mathrm{~min}$ to $2.59 \mathrm{mg} / \mathrm{ml}$ at $20 \mathrm{mins}$. The drastic change of reduction of bile acid concentration is seen during the first 20 mins after a meal then followed to maintain a constant decrease in its concentration wherein compartment $\mathrm{X}_{3}$ at 60 mins it's $1.88 \mathrm{mg} / \mathrm{ml}$ and at $120 \mathrm{mins}$ it's $1.53 \mathrm{mg} / \mathrm{ml}$.

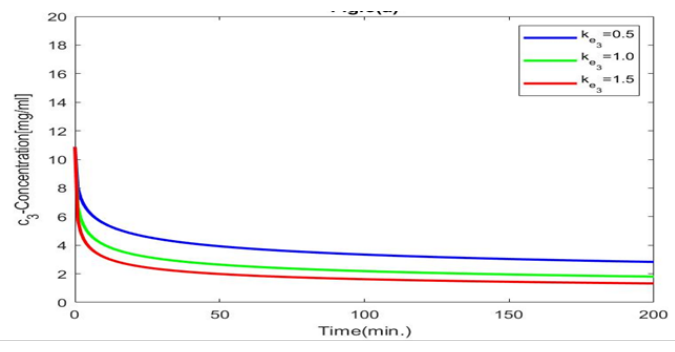

A

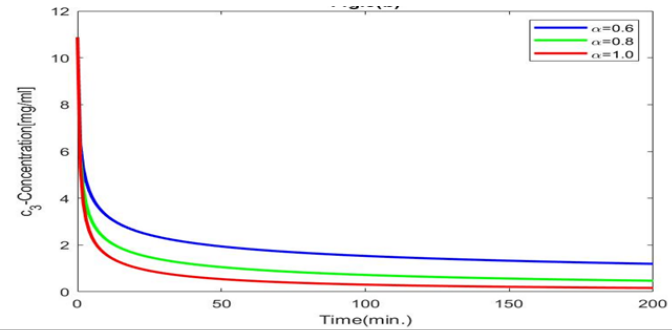

B

Fig 3. (a): Bile concentration in Gallbladder when $k_{e_{3}}=0.5,1.0$, and 1.5 , and $\alpha=0.5$. (b): Bile concentration in Gallbladder when $k_{e_{3}}=1.0$, and $\alpha=0.6,0.8$, and 1.0 . 
Here, the Figure $3 \mathrm{~b}$ graphical result estimates the decreases in bile acid concentration in the gallbladder when $k_{e_{3}}=1.0 / \mathrm{min}$; and at $\alpha=0.6,0.8$, and 1.0 the bile acid concentration at $20 \mathrm{mins}$ was found to be $2.61 \mathrm{mg} / \mathrm{m}, 1.64 \mathrm{mg} / \mathrm{ml}, \mathrm{and} 1.04 \mathrm{mg} / \mathrm{ml}$ respectively and further gradually decreases. As the $\alpha$ value increases the bile acid concentration decreases and the severity of biliary fistula can be analyzed with the application of the FODE A Caputo model irrespective of the change in the rate of resorption from the gallbladder $k_{e_{3}}$.

Considering case-2 (Figure 4a), bile acid concentration by mathematical simulation is analyzed when the rate of evacuation is low, and resorption of bile is high from the gallbladder due to chronic cholecystitis ${ }^{(3)}$.

The Figure 4a graph indicates that at an increased rate of resorption and evacuation from the gallbladder and $\alpha=0.5$, comparative to normal i.e. Figure 2 the bile acid concentration increases in the intestine and liver due to the increases in synthesis of bile, as more of bile is reabsorbed in systemic blood and storage of bile in gallbladder decreases. So, when $\mathrm{k}_{b}=$ 0.25 and $k_{e_{3}}=0.5$ the bile acid concentration in compartment $\mathrm{X}_{1}, \mathrm{X}_{2}$ and $\mathrm{X}_{3}$ was found to be $53.38 \mathrm{mg} / \mathrm{ml}, 12 \mathrm{mg} / \mathrm{ml}$ and 10.88 $\mathrm{mg} / \mathrm{ml}$ at $0 \mathrm{~min}$ and $38.99 \mathrm{mg} / \mathrm{ml}, 17.02 \mathrm{mg} / \mathrm{ml}$ and $4.99 \mathrm{mg} / \mathrm{ml}$ at $20 \mathrm{mins}$ respectively. The next condition where $\mathrm{k}_{b}=0.15$ and $k_{e_{3}}=1.0$, the bile acid concentration in compartments $\mathrm{X}_{1}, \mathrm{X}_{2}$ and $\mathrm{X}_{3}$ was found to be $37.68 \mathrm{mg} / \mathrm{ml}, 16.59 \mathrm{mg} / \mathrm{ml}, 3.68 \mathrm{mg} / \mathrm{ml}$ at 20 mins; whereas when $\mathrm{k}_{b}=0.01$ and $k_{e_{3}}=1.5$ the bile acid concentration was found to be $36.71 \mathrm{mg} / \mathrm{ml}, 16.26 \mathrm{mg} / \mathrm{ml}$ and 2.97 $\mathrm{mg} / \mathrm{ml}$ in compartment $\mathrm{X}_{1}, \mathrm{X}_{2}$ and $\mathrm{X}_{3}$ respectively.

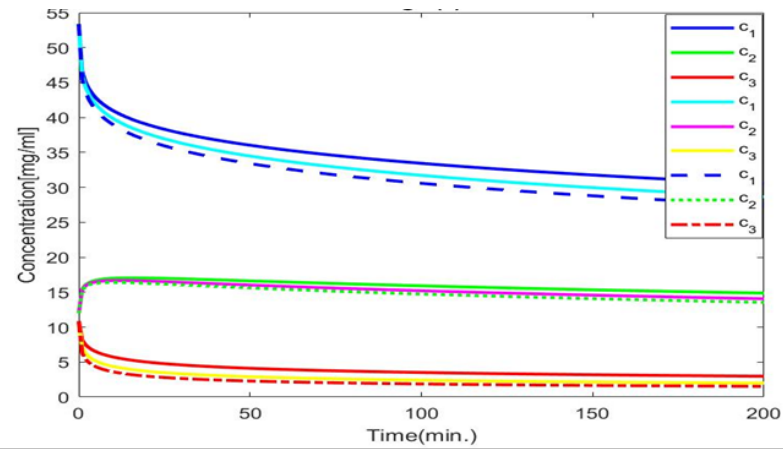

A

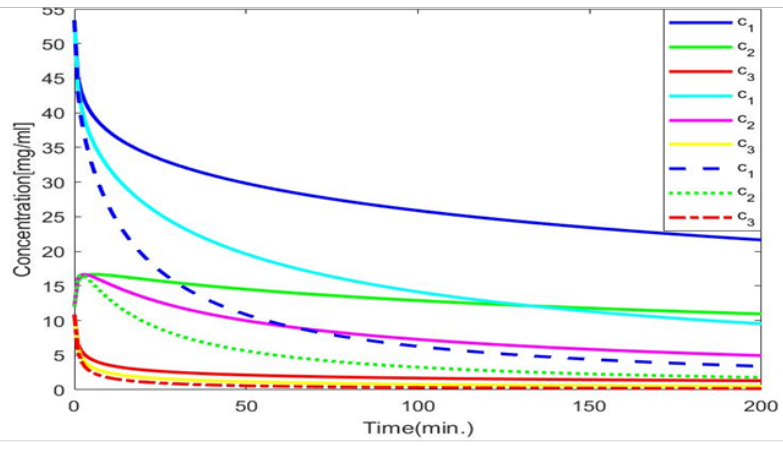

B

Fig 4. (a) Bile concentration in Intestine, Liver, and Gallbladder whenk $k_{b}=0.25,0.15$, and 0.01 , and $k_{e_{3}}=0.5,1.0$, and 1.5 , and $\alpha=0.5$. (b) Bile concentration in Intestine, Liver, and Gallbladder when $\mathrm{k}_{b}=0.6$, and $k_{e_{3}}=1.0$, and $\alpha=0.6,0.8$, and 1.0.

With the condition in Figure $4 \mathrm{~b}$, the rate of evacuation and rate of resorption is assumed to be high and constant $\mathrm{k}_{b}=0.15$ and $k_{e_{3}}=1.0$ and also the $\alpha$ values increase i.e., $0.6,0.8$, and 1.0 to these assumptions the bile acid concentration immensely decreases in intestine and gallbladder due to consequent increase in $\alpha$, i.e. at $\alpha=0.6$ the concentration is $34.36 \mathrm{mg} / \mathrm{ml}$ and 2.87 $\mathrm{mg} / \mathrm{ml}$; at $\alpha=0.8$ it is $27.05 \mathrm{mg} / \mathrm{ml}$ and $1.80 \mathrm{mg} / \mathrm{ml}$; at $\alpha=1.0$ the concentration is $19.42 \mathrm{mg} / \mathrm{ml}$ and $1.14 \mathrm{mg} / \mathrm{ml} \mathrm{in} \mathrm{compartment}$ $\mathrm{X}_{1}$ and $\mathrm{X}_{3}$ respectively at $20 \mathrm{mins}$ and conversely in liver the bile acid concentration increases from $12 \mathrm{mg} / \mathrm{ml}$ at $0 \mathrm{~min}$ to 15.99 $\mathrm{mg} / \mathrm{ml}$ at 20 mins. Such estimation indicates that irrespective of the high-rate constant of bile, the mathematical simulation using the FODE A Caputo model helps to understand the abnormality condition of the biliary system due to varying bile acid concentration with different fractional order.

The case-3 (Figure 5a) estimates bile acid concentration in the condition of cholecystectomy when the rate of secretion of bile in the intestine is 0 and the rate of resorption is also 0 (15).

The condition of cholecystectomy explains that the bile is diverted outside instead from the gallbladder to the intestine, thus $\mathrm{k}_{b}=0.0 / \mathrm{min}$ and $k_{e_{3}}=0$. When $\alpha$ is 0.5 , an increase in bile acid concentration in the gallbladder $10.88 \mathrm{mg} / \mathrm{ml}$ at $0 \mathrm{~min}$ and 14.29 $\mathrm{mg} / \mathrm{ml}$ at $20 \mathrm{mins}$; and decrease in the intestine $53.38 \mathrm{mg} / \mathrm{ml}$ at $0 \mathrm{~min}$ and $36.65 \mathrm{mg} / \mathrm{ml}$ at 20 mins is seen in Figure $5 \mathrm{a}$. 


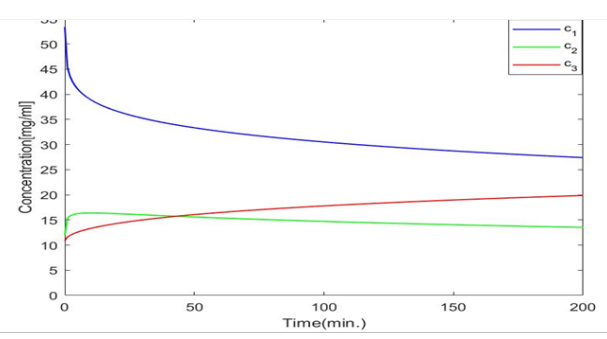

A

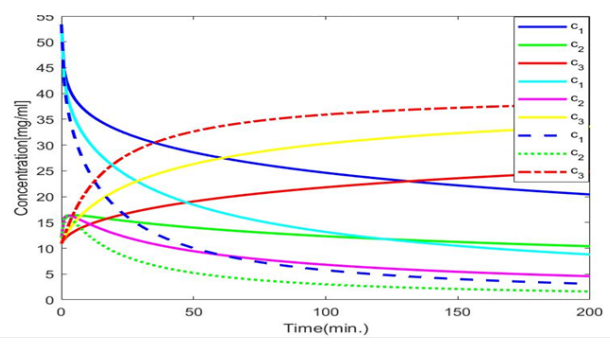

B

Fig 5. (a) Bile concentration in Intestine, Liver, and Gallbladder whenk $b_{b}=0$, and $k_{e_{3}}=0$, and $\alpha=0.5$. (b): Bile concentration in Intestine, Liver, and Gallbladder when $\mathrm{k}_{b}=0.0, k_{e_{3}}=1.0$, and $\alpha=0.6,0.8$, and 1.0 .

With an increase in $\alpha$ value as in Figure 5b, the bile acid concentration drastically increased in the gallbladder which gets reabsorbed into the blood, and immensely decreased in the intestine and liver which further fails to perform lipid metabolism in the intestine. The fixed constant of $\mathrm{k}_{b}=0.0 / \mathrm{min}$ and $k_{e_{3}}=0$ and when $\alpha=0.6$ the bile acid concentration in compartment $\mathrm{X}_{3}$ increases from an initial value of $10.88 \mathrm{mg} / \mathrm{ml}$ to $16.13 \mathrm{mg} / \mathrm{ml}$ at $20 \mathrm{mins}$, whereas in compartment $\mathrm{X}_{1}$ bile acid concentration was found to be $33.21 \mathrm{mg} / \mathrm{ml}$ at $20 \mathrm{mins}$ and in compartment $X_{2}$ bile acid concentration increases till $20 \mathrm{mins}$ from $12 \mathrm{mg} / \mathrm{ml}$ to $15.55 \mathrm{mg} / \mathrm{ml}$, after 20 mins the concentration in compartment $X_{2}$ gradually decreases and found to be $13.59 \mathrm{mg} / \mathrm{ml}$ at $60 \mathrm{mins}$. $\alpha=0.8$, at 0,20 and 60 mins the concentration in compartment $\mathrm{X}_{1}, \mathrm{X}_{2}, \mathrm{X}_{3}$ was found to be $53.3808,12 \mathrm{mg} / \mathrm{ml}, 10.88 \mathrm{mg} / \mathrm{ml}$; $25.80 \mathrm{mg} / \mathrm{ml}, 12.84 \mathrm{mg} / \mathrm{ml}, 20.98 \mathrm{mg} / \mathrm{ml}$; and $16.99 \mathrm{mg} / \mathrm{ml}, 8.72 \mathrm{mg} / \mathrm{ml}, 27.39 \mathrm{mg} / \mathrm{ml}$.

The intestinal manifestation is taken as case- 4 (Figure 6 a), where varying bile acid concentration is estimated due to an increase in the synthesis of bile in the intestine, due to the increased elimination of bile from the intestine to compensate for the huge loss of bile due to ileal resection ${ }^{(4,10)}$.

The Figure 6a mathematically investigates the bile acid concentration in the case of ileal resection, where the rate of bile synthesis in the intestine increases due to the increase in loss of bile i.e., $k_{e_{1}}$, whereas $\alpha$ remains 0.5 . The result shows that bile acid concentration is initially high in compartment $X_{1}$ compared to normal conditions i.e., Figure $2 \mathrm{a}$, but when the rate of elimination $k_{e_{1}}$ increases than the concentration of bile acid in the intestine gradually decreases, in the liver increases, and the gallbladder slightly increases. When $\mathrm{x}_{01}=4 \times 10^{4}$ and $k_{e_{1}}=0.06$, the bile acid concentration was found to be $71.17 \mathrm{mg} / \mathrm{ml}$ at $0 \mathrm{~min}$ and $48.38 \mathrm{mg} / \mathrm{ml}$ at $20 \mathrm{mins}$ in compartment $\mathrm{X}_{1} ; 10.88 \mathrm{mg} / \mathrm{ml}$ at $0 \mathrm{~min}$ and $6.32 \mathrm{mg} / \mathrm{ml}$ at $20 \mathrm{mins}$ in compartment $\mathrm{X}_{3}$; whereas in compartment $\mathrm{X}_{2}$ the bile acid concentration initially increases from $12 \mathrm{mg} / \mathrm{ml}$ to $20.13 \mathrm{mg} / \mathrm{ml}$ at $20 \mathrm{mins}$ than gradually decreases to $19.50 \mathrm{mg} / \mathrm{ml}$ at 60 mins. The other condition where $\mathrm{x}_{01}=5 \times 10^{4}$ and $k_{e_{1}}=0.08$, the bile acid concentration was found to be $88.96 \mathrm{mg} / \mathrm{ml}$ at $0 \mathrm{~min}$ and $56.46 \mathrm{mg} / \mathrm{ml}$ at $20 \mathrm{mins}$ in compartment $X_{1} ; 10.88 \mathrm{mg} / \mathrm{ml}$ at $0 \mathrm{~min}$ and $6.56 \mathrm{mg} / \mathrm{ml}$ at 20 mins in compartment $\mathrm{X}_{3}$; conversely in compartment $\mathrm{X}_{2}$ bile acid concentration increases initially from $12 \mathrm{mg} / \mathrm{ml}$ to 22.83 $\mathrm{mg} / \mathrm{ml}$ and after $20 \mathrm{mins}$ it gradually decreases to $21.95 \mathrm{mg} / \mathrm{ml}$ at 60 mins. The next assumption considered as $\mathrm{x}_{01}=6 \times 10^{4}$ and $k_{e_{1}}=0.1$, the bile acid concentration was found to be $106.76 \mathrm{mg} / \mathrm{ml}$ at $0 \mathrm{~min}$ and $64.17 \mathrm{mg} / \mathrm{ml}$ at $20 \mathrm{mins}$ in compartment $\mathrm{X}_{1}$, $12 \mathrm{mg} / \mathrm{ml}$ at $0 \mathrm{~min}$ and $25.40 \mathrm{mg} / \mathrm{ml}$ at 20 mins in compartment $X_{2}$ than decreases gradually to $24.22 \mathrm{mg} / \mathrm{ml}$ at $60 \mathrm{mins}$.

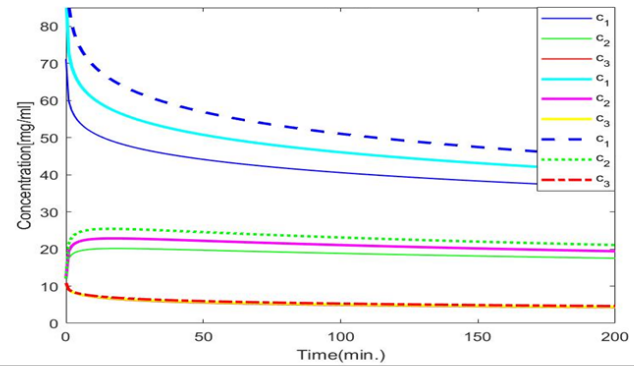

A

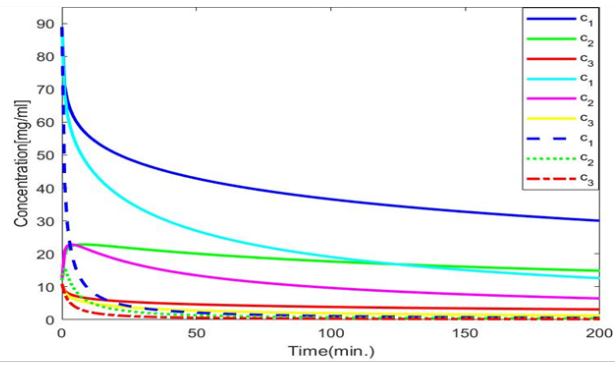

B

Fig 6. (a) Bile concentration in Intestine, Liver, and Gallbladder whenx $\mathrm{x}_{01}=4 \times 10^{4} ; 5 \times 10^{4} ; 6 \times 10^{4}$, and $k_{e_{1}}=0.06,0.08$, and 0.1 , and $\alpha=0.5$. (b) Bile concentration in Intestine, Liver, and Gallbladder when $\mathrm{x}_{01}=5 \times 10^{4}$, and $k_{e_{1}}=0.08$, and $\alpha=0.6,0.8$, and 1.0 
Considering the assumption made for Figure 6a analysis, with the increased synthesis of bile and elimination rate in the intestine, and the application of fractional order differential equation represents the overall results where the drastic decrease in bile acid concentration in intestine and liver is observed which indicate that bile pool size decreases and efficiency of bile storage in gallbladder also decreases. The $\mathrm{x}_{01}=5 \times 10^{4}$ and $k_{e_{1}}=0.08$ remains constant the initial concentration was found to be constant in varying $\alpha$ value i.e., at $0 \mathrm{~min}$ bile acid concentration is $88.96 \mathrm{mg} / \mathrm{ml}, 12 \mathrm{mg} / \mathrm{ml}, 10 \mathrm{mg} / \mathrm{ml} \mathrm{in} \mathrm{compartment} \mathrm{X}_{1}, \mathrm{X}_{2}$ and $\mathrm{X}_{3}$ respectively, at $\alpha=0.6$ and at 20 mins the bile acid concentration is $50.54 \mathrm{mg} / \mathrm{ml}, 22.16 \mathrm{mg} / \mathrm{ml}, 5.68 \mathrm{mg} / \mathrm{ml} \mathrm{respectively}$. At $\alpha=0.8$ the bile acid concentration was found to be $38.44 \mathrm{mg} / \mathrm{ml}, 18.43 \mathrm{mg} / \mathrm{ml}, 4.09 \mathrm{mg} / \mathrm{ml}$ respectively. Finally, at $\alpha=1.0$ the concentration at $20 \mathrm{mins}$ is $26.73 \mathrm{mg} / \mathrm{ml}, 13.34 \mathrm{mg} / \mathrm{ml}, 2.75 \mathrm{mg} / \mathrm{ml}$ respectively.

The case-5 (Figure 7a) investigates bile acid concentration in an etiological condition where the mass of bile acid in the intestine and gallbladder is high and low respectively and the rate of reabsorption of bile from the liver to systemic circulation also increases due to portal-systemic venous shunting ${ }^{(23)}$.

The condition of portal venous shunting is considered to evaluate bile acid concentration in the intestine, liver, and gallbladder. In the case of portal venous shunting the mass of bile synthesis increases in the intestine and decreases in the gallbladder, with an increased rate of reabsorption of bile from the liver into systemic circulation and $\alpha$ remains 0.5 . The graphical observation in Figure 7a shows a decrease in bile acid concentration in the liver and gallbladder due to venous portal shunting. When $\mathrm{x}_{01}=4 \times 10^{4}, \mathrm{x}_{03}=8000, k_{e_{2}}=0.03$, the bile acid concentration in compartment $\mathrm{X}_{1}, \mathrm{X}_{2}$, and $\mathrm{X}_{3}$ was found to be $71.17 \mathrm{mg} / \mathrm{ml}, 12 \mathrm{mg} / \mathrm{ml}$ and $10.66 \mathrm{mg} / \mathrm{ml}$ at $0 \mathrm{~min}$ and $49.74 \mathrm{mg} / \mathrm{ml}, 20.43 \mathrm{mg} / \mathrm{ml}, 6.26 \mathrm{mg} / \mathrm{ml}$ at $20 \mathrm{mins}$ respectively. Consequently, when $\mathrm{x}_{01}=5 \times 10^{4}, \mathrm{x}_{03}=6000$ and $k_{e_{2}}=0.05$, the bile acid concentration is $88.96 \mathrm{mg} / \mathrm{ml}, 12 \mathrm{mg} / \mathrm{ml}, 8 \mathrm{mg} / \mathrm{ml}$ at $0 \mathrm{~min}$ and $58.41 \mathrm{mg} / \mathrm{ml}, 22.9 \mathrm{mg} / \mathrm{ml}, 5.36 \mathrm{mg} / \mathrm{ml}$ at $20 \mathrm{mins}$ in compartment $\mathrm{X}_{1}, \mathrm{X}_{2}$, and $\mathrm{X}_{3}$ respectively. Lastly assuming $\mathrm{x}_{01}=6 \times 10^{4}, \mathrm{x}_{03}=4000$ and $k_{e_{2}}=0.07$, the bile acid concentration was found to be $106.76 \mathrm{mg} / \mathrm{ml}, 12 \mathrm{mg} / \mathrm{ml}, 5.33 \mathrm{mg} / \mathrm{ml}$ at 0 min and $66.93 \mathrm{mg} / \mathrm{ml}, 25.24 \mathrm{mg} / \mathrm{ml}$ and $4.45 \mathrm{mg} / \mathrm{ml}$ at $20 \mathrm{mins}$ in $\mathrm{X}_{1}, \mathrm{X}_{2}$, and $\mathrm{X}_{3}$ respectively.

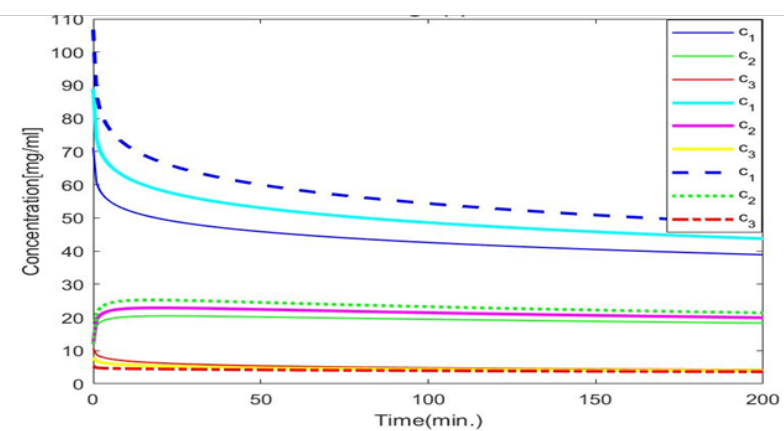

A

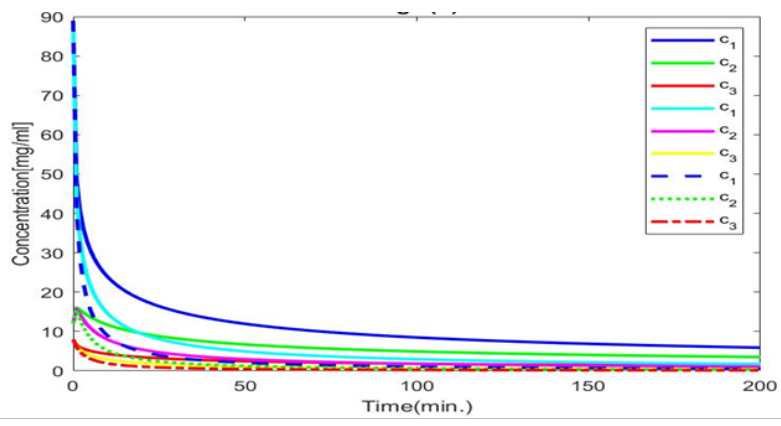

B

Fig 7. (a) Bile concentration in Intestine, Liver, and Gallbladder when $\mathrm{x}_{01}=4 \times 10^{4} ; 5 \times 10^{4} ; 6 \times 10^{4} ; \mathrm{x}_{03}=8000,6000,4000$, and $k_{e_{2}}=0.03,0.05$, and 0.07 , and $\alpha=0.5$. (b) Bile concentration in Intestine, Liver, and Gallbladder when $\mathrm{x}_{01}=5 \times 10^{4} ; \mathrm{x}_{03}=6000$; $k_{e_{2}}=0.05$, and $\alpha=0.6,0.8$, and 1.0 .

With the application of an increase in $\alpha$ value, the severity of venous portal shunting is seen in all the compartments. Here when $\mathrm{x}_{01}=5 \times 10^{4} ; \mathrm{x}_{03}=6000 ; k_{e_{2}}=0.05$ remains constant and at 0 min in varying $\alpha$ values the bile acid concentration is $88.96 \mathrm{mg} / \mathrm{ml}, 12 \mathrm{mg} / \mathrm{ml}$ and $8 \mathrm{mg} / \mathrm{ml}$ in compartment $\mathrm{X}_{1}, \mathrm{X}_{2}$, and $\mathrm{X}_{3}$ respectively. At 20 mins when $\alpha=0.6$, the bile acid concentration is $18.07 \mathrm{mg} / \mathrm{ml}, 9.5 \mathrm{mg} / \mathrm{ml}, 3.47 \mathrm{mg} / \mathrm{ml}$; when $\alpha=0.8$ the concentration is $9.38 \mathrm{mg} / \mathrm{ml}, 5.4 \mathrm{mg} / \mathrm{ml}, 1.97 \mathrm{mg} / \mathrm{ml}$; when $\alpha=1.0$ the concentration is $4.85 \mathrm{mg} / \mathrm{ml}, 2.91 \mathrm{mg} / \mathrm{ml}, 1.07 \mathrm{mg} / \mathrm{ml}$ in compartment $\mathrm{X}_{1}, \mathrm{X}_{2}$, and $\mathrm{X}_{3}$ respectively.

Finally, case- 6 (Figure $8 \mathrm{a}$ ) and one of the most common complications seen in the population is gallstone, where the varying bile acid concentration is studied considering the decrease rate of bile filling in the gallbladder due to closure of ductal passage from the liver to gallbladder ${ }^{(13)}$.

Figure $8 \mathrm{a}$ and Figure $8 \mathrm{~b}$ explain the mathematical simulation to understand the condition of gallstone where the rate of bile filling into gallbladder decreases due to which bile acid concentration in liver and gallbladder becomes approximately equal with $\alpha$ is 0.5 as shown in Figure 8a. In Figure 8a, when $k_{g}=0.52,0.37$, and 0.25 the initial bile acid concentration at 0 min $53.38 \mathrm{mg} / \mathrm{ml}, 12 \mathrm{mg} / \mathrm{ml}, 10.88 \mathrm{mg} / \mathrm{ml}$ in compartment $\mathrm{X}_{1}, \mathrm{X}_{2}$, and $\mathrm{X}_{3}$ respectively which drastically decreases in intestine at 20 mins the concentration is $36.15 \mathrm{mg} / \mathrm{ml}$ when $k_{g}=0.52,37.11 \mathrm{mg} / \mathrm{ml}$ when $k_{g}=0.37,38.08 \mathrm{mg} / \mathrm{ml}$ when $k_{g}=0.25$. And gradual increases of bile acid concentration in liver at $20 \mathrm{mins}$, when $k_{g}=0.52$ the concentration is to $11.57 \mathrm{mg} / \mathrm{ml}, k_{g}=0.37$ 
the concentration is $12.99 \mathrm{mg} / \mathrm{ml}, k_{g}=0.25$ the concentration is $14.41 \mathrm{mg} / \mathrm{ml}$. The drastic decrease of bile acid concentration in the gallbladder to $13.03 \mathrm{mg} / \mathrm{ml}$ at $20 \mathrm{mins}$ when $k_{g}=0.52,11.33 \mathrm{mg} / \mathrm{ml}$ when $k_{g}=0.37$, and $9.63 \mathrm{mg} / \mathrm{ml}$ when $k_{g}=0.25$.

Whereas, with increasing $\alpha$ value the bile acid concentration drastically decreases in all the compartments as shown in Figure $8 \mathrm{~b}$. At varying $\alpha$, the initial concentration was found to be $53.38,12,10.88 \mathrm{mg} / \mathrm{ml}$ in compartment $\mathrm{X}_{1}, \mathrm{X}_{2}$, and $\mathrm{X}_{3}$ respectively. When $\alpha=0.6$ and at 20 mins, the concentration was found to be $32.98,11.89$, and $10.73 \mathrm{mg} / \mathrm{ml} \mathrm{in} \mathrm{X}_{1}, \mathrm{X}_{2}$, and $\mathrm{X}_{3}$ respectively, whereas at $\alpha=0.8$ and 1.0 the concentrations are $24.20,9,8.53 \mathrm{mg} / \mathrm{ml}$, and $16.07,6.05,5.88 \mathrm{mg} / \mathrm{ml}$ respectively in compartment $\mathrm{X}_{1}, \mathrm{X}_{2}$, and $\mathrm{X}_{3}$.

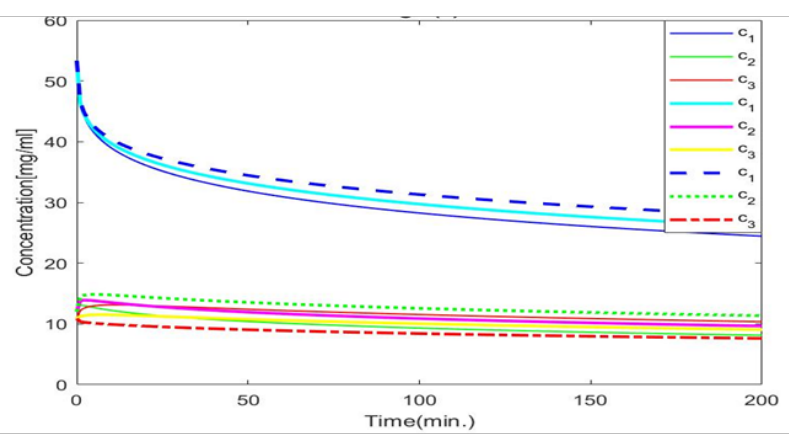

A

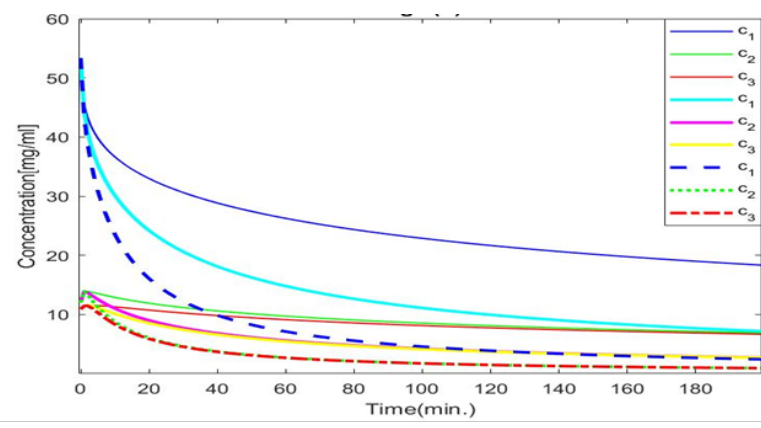

B

Fig 8. (a) Bile concentration in Intestine, Liver, and Gallbladder when $k_{g}=0.52,0.37$, and 0.25 , and $\alpha=0.5$. (b) Bile concentration in Intestine, Liver, and Gallbladder when $k_{g}=0.37$, and $\alpha=0.6,0.8$, and 1.0.

The varying bile acid concentration $\left[c=\frac{m}{V} ; \mathrm{m}=\right.$ amount of bile acid; $\mathrm{V}=$ volume of bile] enables us to understand the severity of clinical manifestation of the biliary system. The biliary circulation is essential physiology of the body which regulates lipid digestion in the intestine ${ }^{(24)}$. As the pathology of the gallbladder and intestine is concerned, the review of literature could assume the change of bile secretion rate in the biliary system, but the bile acid concentration in such pathological condition remains unsolved $^{(4)}$. The simulation using mathematical tools helps to understand various physiological and pathological conditions of the biliary system. The application of the mathematical method and in silico simulation estimates the normal physiology of the biliary system indicating the concentration of bile acid in compartment $\mathrm{X}_{1}, \mathrm{X}_{2}$, and $\mathrm{X}_{3}$ as per Figure 2(a). With the reference to the result found in 2(a), the varying conditions of bile acid secretion rate are considered as per the pathological case to find bile acid concentration in respective compartments. All the cases were analyzed by applying a fractional differential equation, and the result estimates indicate the severity of the condition due to an increase or decrease in bile acid concentration in all the compartments. Every case considered could help to analyze bile acid concentration; the severity of the case was analyzed only when fractional derivative was applied. The results delineate that as the order of fraction increases the bile acid concentration decreases or increases with all the applicable model parameter assumptions based upon the case of pathophysiology.

The literature by scientist Hoffman explains the physiological disturbances of the biliary system in case of various liver and intestinal disorders, and the literature reviewed to explain the intracellular and extracellular toxicity held due to abnormal secretion of bile in the biliary system ${ }^{(3,25)}$. The more evidence regarding the change in bile acid concentration based on calorie intake enhanced our focus of research to estimate the change in bile acid concentration in different pathological states $^{(26)}$. The varying calorie drinks were ingested by subject volunteers and the change in plasma bile acid concentration and pharmacokinetic absorption of bile acid were estimated by Guiastrennec et al., ${ }^{(27)}$. Another study proposed by Chiang and Ferrell gives a strong review-based estimation regarding the action of bile acid on bile acid- receptor in case of metabolic disorder and thus cause physiological disturbances in bile acid secretion rate and its concentration ${ }^{(6)}$. The study by Lavoie et al. focus to estimate the cause of gallstone pathology and the results of research explains that the cholesterol saturation and hydrophobicity is a cause of disruption of gallbladder smooth muscle which in turn proved to be a prime cause of gallstone formation; also, the increase in intestinal transit time trigger the formation of gallstone, thus the gallstone is also considered to be an intestinal disorder ${ }^{(17)}$. Moreover, the scientist Khan et al. concluded the effect of HEV by modeling its dynamic in the society and by using fractional derivative Caputo model they could able to find the viral load, severity, and recovery rate of hepatitis in society ${ }^{(28)}$, similarly by using fractional derivative A Caputo model the bile acid concentration can be estimated at non-integer condition which estimates the severity of abnormality in enterohepatic circulation. 


\section{Conclusion}

Overlooking into all the research reviews, the extreme note was required to understand the varying bile acid concentration in different pathophysiological cases. Additively, the application of mathematical simulation using fractional differential equation enhanced the case results distinctly and enabled us to understand the concentration of bile acid at non-inter case explaining the varying pathological severity of intestine, liver, and gallbladder. The results analysis will encourage the researcher to understand the bile acid action in various organs based on its concentration and an appropriate treatment regimen can be designed accordingly.

\section{Acknowledgements}

This work is not supported by any funding agency. And thank you for the suggestions given by the anonymous referees.

\section{References}

1) Boyer JL. Bile formation and secretion. Comprehensive Physiology. 2013;3(3):1035-1078. Available from: https://doi.org/10.1002/cphy.c120027.

2) Esteller A. Physiology of bile secretion. World Journal of Gastroenterology. 2008;14(37):5641-5649. Available from: https://dx.doi.org/10.3748/wjg.14.5641.

3) Hofmann AF. The enterohepatic circulation of bile acids in mammals: form and functions. Frontiers in Bioscience. 2009;14:2584-2598. Available from: https://dx.doi.org/10.2741/3399.

4) Skouras T, Dodd S, Prasad Y, Rassam J, Morley N, Subramanian S. Brief report: length of ileal resection correlates with severity of bile acid malabsorption in Crohn's disease. International Journal of Colorectal Disease. 2019;34(1):185-188. Available from: https://dx.doi.org/10.1007/s00384-018-3144-1.

5) Guiastrennec B, Sonne DP, Bergstrand M, Vilsbøll T, Knop FK, Karlsson MO. Model-Based Prediction of Plasma Concentration and Enterohepatic Circulation of Total Bile Acids in Humans. CPT: Pharmacometrics \& Systems Pharmacology. 2018;7(9):603-612. Available from: https://dx.doi.org/10. $1002 /$ psp4.12325.

6) Chiang JYL, Ferrell JM. Bile Acid Metabolism in Liver Pathobiology. Gene Expression. 2018;18(2):71-87. Available from: https://dx.doi.org/10.3727/ $105221618 \times 15156018385515$.

7) Vlahcevic ZR, Heuman DM, Hylemon PB. Regulation of bile acid synthesis. Hepatology. 1991;13(3):590-600. Available from: https://dx.doi.org/10.1002/ hep.1840130331.

8) Erpecum KJV, Berge-Henegouwen GPV. Gallstones: an intestinal disease? Gut. 1999;44(3):435-438. Available from: https://dx.doi.org/10.1136/gut.44.3. 435.

9) Kasumova GG, Tabatabaie O, Najarian RM, Callery MP, Ng SC, Bullock AJ, et al. Surgical management of gallbladder cancer: simple versus extended cholecystectomy and the role of adjuvant therapy. Annals of surgery. 2017;266(4):625-631.

10) Andrianello S, Marchegiani G, Malleo G, Pollini T, Bonamini D, Salvia R. Biliary fistula after pancreaticoduodenectomy: data from 1618 consecutive pancreaticoduodenectomies. HPB. 2017;19(3):264-269. Available from: https://dx.doi.org/10.1016/j.hpb.2016.11.011.

11) Materne R, Beers BEV, Gigot JF, Jamart J, Geubel A, Pringot J. Extrahepatic biliary obstruction: magnetic resonance imaging compared with endoscopic ultrasonography. Endoscopy. 2000;32(01):3-9.

12) Franchi-Abella S, Gonzales E, Ackermann O, Branchereau S, Pariente D, Guérin F. Congenital portosystemic shunts: diagnosis and treatment. Abdominal Radiology. 2018;43(8):2023-2036. Available from: https://dx.doi.org/10.1007/s00261-018-1619-8.

13) Suchy FJ, Ananthanarayanan M. Bile salt excretory pump: biology and pathobiology. Journal of pediatric gastroenterology and nutrition. 2006;43(1):10-16.

14) Zulpo M, Balbus J, Kuropka P, Kubica K. A model of gallbladder motility. Computers in Biology and Medicine. 2018;93:139-148. Available from: https://dx.doi.org/10.1016/j.compbiomed.2017.12.018.

15) Colak Y, Bozbey G, Erim T, Caklili OT, Ulasoglu C, Senates E, et al. Impaired Gallbladder Motility and Increased Gallbladder Wall Thickness in Patients with Nonalcoholic Fatty Liver Disease. Journal of Neurogastroenterology and Motility. 2016;22(3):470-476. Available from: https://dx.doi.org/10.5056/ jnm15159.

16) Li S, Li C, Wang W. Bile acid signaling in renal water regulation. American Journal of Physiology-Renal Physiology. 2019;317(1):73-76.

17) Lanzini A, Northfield TC. Bile acid therapy. Alimentary pharmacology \& therapeutics. 1990;4(1):1-24.

18) Khan MA, Atangana A. Modeling the dynamics of novel coronavirus (2019-nCov) with fractional derivative. Alexandria Engineering Journal. 2020;59(4):2379-2389. Available from: https://dx.doi.org/10.1016/j.aej.2020.02.033.

19) Crosignani A, Setchell KDR, Invernizzi P, Larghi A, Rodrigues CMP, Podda M. Clinical Pharmacokinetics of Therapeutic Bile Acids. Clinical Pharmacokinetics. 1996;30(5):333-358. Available from: https://dx.doi.org/10.2165/00003088-199630050-00002.

20) Grosell M, O’Donnell MJ, Wood CM. Hepatic versus gallbladder bile composition: in vivo transport physiology of the gallbladder in rainbow trout. American Journal of Physiology-Regulatory, Integrative and Comparative Physiology. 2000;278(6):R1674-R1684. Available from: https://dx.doi.org/10. 1152/ajpregu.2000.278.6.r1674.

21) Nathanson MH, Boyer JL. Mechanisms and regulation of bile secretion. Hepatology. 1991;14(3):551-566. Available from: https://dx.doi.org/10.1002/hep. 1840140324.

22) Corbett CL, Bartholomew TC, Billing BH, Summerfield JA. Urinary excretion of bile acids in cholestasis: evidence for renal tubular secretion in man. Clinical science. 1979;61(6):773-780.

23) Fatmawati MA, Bonyah E, Hammouch Z, Shaiful EM. A mathematical model of tuberculosis (TB) transmission with children and adults groups: A fractional model. AIMS Mathematics. 2020;5(4):2813-2855.

24) Yeh CY, Chung-Davidson YW, Wang H, Li K, Li W. Intestinal synthesis and secretion of bile salts as an adaptation to developmental biliary atresia in the sea lamprey. Proceedings of the National Academy of Sciences. 2012;109(28):11419-11424. Available from: https://dx.doi.org/10.1073/pnas.1203008109.

25) Gurantz D, Hofmann AF. Influence of bile acid structure on bile flow and biliary lipid secretion in the hamster. American Journal of PhysiologyGastrointestinal and Liver Physiology. 1984;247(6):G736-G748. Available from: https://dx.doi.org/10.1152/ajpgi.1984.247.6.g736. 
26) Jazrawi RP, Pazzi P, Petroni ML, Prandini N, Paul C, Adam JA. Postprandial gallbladder motor function: Refilling and turnover of bile in health and in cholelithiasis. Gastroenterology. 1995;109(2):582-591. Available from: https://dx.doi.org/10.1016/0016-5085(95)90348-8.

27) Guiastrennec B, Sonne DP, Hansen M, Bagger JI, Lund A, Rehfeld JF, et al. Mechanism-Based Modeling of Gastric Emptying Rate and Gallbladder Emptying in Response to Caloric Intake. CPT: Pharmacometrics \& Systems Pharmacology. 2016;5(12):692-700. Available from: https://dx.doi.org/10. 1002/psp4.12152.

28) Khan MA, Hammouch Z, Baleanu D. Modeling the dynamics of hepatitis E via the Caputo-Fabrizio derivative. Mathematical Modelling of Natural Phenomena. 2019;14(3):311. Available from: https://dx.doi.org/10.1051/mmnp/2018074. 